\title{
Lasofoxifene: Evidence of its therapeutic value in osteoporosis
}

This article was published in the following Dove Press journal:

Core Evidence

30 June 2009

Number of times this article has been viewed

\section{Luigi Gennari \\ Daniela Merlotti \\ Vincenzo De Paola \\ Ranuccio Nuti \\ Department of Internal Medicine, Endocrine-Metabolic Sciences and Biochemistry, University of Siena, Policlinico Le Scotte 53100-Siena, Italy}

Introduction: Osteoporosis is a skeletal disorder characterized by compromised bone strength and increased risk of fracture. It is a common disorder in elderly subjects and represents a major public health problem, affecting up to $40 \%$ postmenopausal women and $15 \%$ of men. Among the several therapeutical interventions, hormone replacement therapy (HRT) was traditionally seen as the gold standard for preventing osteoporotic fractures in postmenopausal women, as well as for the management of menopausal symptoms. However HRT, especially if administered long-term, may lead to an increased risk of breast and, when unopposed by progestins, endometrial cancers. Alternative therapies include bisphosphonates and raloxifene, a selective estrogen receptor modulator (SERM). While the former have been associated with suboptimal adherence, the latter was considerably less potent than estrogen and its effect in the prevention of nonvertebral fractures remain uncertain.

Aims: The purpose of this article is to review the clinical trials of lasofoxifene, a new SERM for the treatment of postmenopausal osteoporosis. The medical literature was reviewed for appropriate articles containing the terms "lasofoxifene" and SERMs".

Evidence review: There are three (phase II or phase III) clinical trials that clearly demonstrate efficacy and safety of this new SERM in the suppression of bone loss and the prevention of vertebral and nonvertebral fractures. Moreover, lasofoxifene treatment also reduced breast cancer risk and the occurrence of vaginal atrophy.

Place in therapy: With its increased potency and efficacy on the prevention of nonvertebral fractures lasofoxifene may be an alternative and cost-effective therapy for osteoporosis in postmenopausal women.

Keywords: osteoporosis, lasofoxifene, SERM, fracture, treatment

Core evidence clinical impact summary for lasofoxifene in the treatment of postmenopausal osteoporosis

\begin{tabular}{|lll|}
\hline Outcome measure & Evidence & Implications \\
\hline $\begin{array}{l}\text { Patient-oriented evidence } \\
\text { Fracture risk reduction }\end{array}$ & Clear & $\begin{array}{l}\text { Reduced risk of vertebral and } \\
\text { nonvertebral fractures in women } \\
\text { with postmenopausal osteoporosis } \\
\text { compared with placebo } \\
\text { Reduced breast cancer incidence } \\
\text { Breast cancer risk } \\
\text { reduction }\end{array}$ \\
& Clear & $\begin{array}{l}\text { (all breast cancers) in postmenopausal } \\
\text { women after three and five years of } \\
\text { treatment compared with placebo } \\
\text { (Continued) }\end{array}$ \\
& &
\end{tabular}

Correspondence: Luigi Gennari

Department of Internal Medicine, Endocrine-Metabolic Sciences and Biochemistry, University of Siena, Viale Bracci I, 53100 Siena, Italy

Tel +39577585364

Fax +39577233446

Email gennari@unisi.it submit your manuscript $\mid$ www.dovepress.com

Dovepress 


\begin{tabular}{|c|c|c|}
\hline \multicolumn{3}{|l|}{ (Continued) } \\
\hline Outcome measure & Evidence & Implications \\
\hline $\begin{array}{l}\text { Improvement of } \\
\text { gynecological symptoms }\end{array}$ & Moderate & $\begin{array}{l}\text { Reduction in vulvar-vaginal atrophy, } \\
\text { without any improvement on hot } \\
\text { flushes with respect to raloxifene }\end{array}$ \\
\hline Uterine safety & Moderate & $\begin{array}{l}\text { No evidence of clinically significant } \\
\text { increase in the incidence of endome- } \\
\text { trial hyperplasia or uterine cancer. } \\
\text { Increased risk for developing uterine } \\
\text { polyps and vaginal bleeding }\end{array}$ \\
\hline $\begin{array}{l}\text { Occurence of venous } \\
\text { thromboembolism }\end{array}$ & Substantial & $\begin{array}{l}\text { Greater than twofold increase in } \\
\text { the risk of venous thromboembolic } \\
\text { events and greater than fourfold } \\
\text { increase in the risk of pulmonary } \\
\text { embolism compared with placebo }\end{array}$ \\
\hline Mortality rate & Limited & $\begin{array}{l}\text { Slight but significant increase in } \\
\text { prevalence of all-cause deaths at } \\
\text { five years in lasofoxifene } 0.25 \mathrm{mg} / \text { day } \\
\text { (but not } 5.0 \mathrm{mg} / \text { day) vs placebo }\end{array}$ \\
\hline \multicolumn{3}{|c|}{ Disease-oriented evidence } \\
\hline $\begin{array}{l}\text { Preservation of bone } \\
\text { quality }\end{array}$ & Substantial & $\begin{array}{l}\text { No pathological bone findings were } \\
\text { identified in bone biopsies after } \\
\text { treatment }\end{array}$ \\
\hline Increase in bone density & Clear & $\begin{array}{l}\text { Prevention of postmenopausal bone } \\
\text { loss, with an increase in BMD at the } \\
\text { lumbar spine and the hip compared } \\
\text { with placebo }\end{array}$ \\
\hline $\begin{array}{l}\text { Suppression of bone } \\
\text { turnover }\end{array}$ & Clear & $\begin{array}{l}\text { Reduction of bone turnover markers } \\
\text { compared with placebo }\end{array}$ \\
\hline \multicolumn{3}{|l|}{ Economic evidence } \\
\hline Cost-effectiveness & No evidence & $\begin{array}{l}\text { Cost-effectiveness studies have not } \\
\text { been performed. If a similar cost will } \\
\text { be established, lasofoxifene treatment } \\
\text { could have improved cost-effectiveness } \\
\text { compared with raloxifene. }\end{array}$ \\
\hline
\end{tabular}

\section{Scope, aims, and objectives}

Lasofoxifene is a new generation selective estrogen receptor modulator (SERM) that has completed the phase III development program for the prevention and treatment of osteoporosis in postmenopausal women. This compound has a remarkably improved oral bioavailability with respect to other SERMs due to increased resistance to intestinal wall glucuronidation. In both preclinical and short-term phase II clinical studies lasofoxifene showed a favorable safety profile and demonstrated a proven efficacy in preventing bone loss and lowering cholesterol levels. The recent results from phase III clinical trials demonstrated the clinical efficacy of this drug in the prevention of fractures and the reduction of breast cancer risk.

The purpose of this article is to review the clinical evidence for the use of lasofoxifene in women after menopause and to discuss how it will fit into the treatment of postmenopausal osteoporosis.

\section{Methods}

Relevant articles were identified on the basis of searches in PubMed and EMBASE databases using the terms "lasofoxifene", "CP-336156", and "selective estrogen receptor modulators". The search was updated on September 30, 2008.

One hundred and seventy-eight articles were found, of which 11 were written in languages other than English and were excluded (Table 1). Within those publications, one report from a phase II clinical trial and 67 review articles were identified. Of the 67 review articles, three provided systematic review of multiple randomized controlled trials and were considered. The phase II clinical study was a two-year comparative trial of the skeletal effects of lasofoxifene and raloxifene in postmenopausal women. Twenty-five further abstracts were identified from the annual meetings of the Endocrine Society and the American Society of Bone and Mineral Research (ASBMR), of which eight were considered relevant. These abstracts presented the results from three 
Table I Evidence base included in the review

\begin{tabular}{lll}
\hline Category & \multicolumn{2}{l}{ Number of records } \\
\cline { 2 - 3 } & Full papers & Abstracts \\
\hline Initial search & 178 & 25 \\
Records excluded & 174 & 17 \\
Records included & 4 & 8 \\
Additional studies identified & 2 & 0 \\
Total records included & 6 & 8 \\
Level I clinical evidence & 3 & 0 \\
(systematic review, meta analysis) & & \\
Level 2 clinical evidence (RCT) & 1 & 8 \\
Level $\geq 3$ clinical evidence & 2 & 0 \\
Trials other than RCT & 0 & 0 \\
Case reports & 0 & 0 \\
Expert committee reports & 2 & 0 \\
Economic evidence & 0 & 0 \\
\hline
\end{tabular}

Notes: For definitions of levels of evidence, see Editorial information on the Core Evidence website, http://www.dovepress.com/core-evidence-journal Abbreviation: RCT, randomized controlled trial.

large, phase III, randomized, double blind, placebo-controlled clinical trials with bone mineral density (BMD) or fractures as a primary end-point: the Osteoporosis Prevention and Lipid Lowering (OPAL) parallel studies, and the Postmenopausal Evaluation and Risk-Reduction With Lasofoxifene (PEARL) study. Each study provided level 2 evidence on the efficacy and safety of lasofoxifene for the treatment of postmenopausal osteoporosis. In addition, two clinical documents about lasofoxifene were available on the Internet, concerning the risk benefit profile of lasofoxifene presented for the 2008 FDA application: the "Reproductive Health Drugs Advisory Committee Briefing Document" and the "Background Document for Meeting of Advisory Committee for Reproductive Health Drugs". These documents provided additional and detailed evidence on the efficacy and safety of lasofoxifene treatment in postmenopausal women. No pharmacoeconomic reports of lasofoxifene were identified.

\section{Disease overview}

Osteoporosis is a skeletal disorder characterized by compromised bone strength and increased risk of fracture. ${ }^{1}$ It is one of the most common disorders in elderly subjects and represents a major public health problem, affecting up to $40 \%$ postmenopausal women and $15 \%$ of men. ${ }^{2}$ Worldwide, osteoporosis is estimated to be present in over 200 million individuals, with 75 million of these in Europe, Japan and the US. ${ }^{3}$ Its clinical significance lies in the occurrence of fractures, involving most commonly the forearm, the vertebral bodies and the hip, but fractures at other sites may be also associated with the disease. Each year in the United States more than 1.5 million people suffer hip, vertebral, and wrist fractures due to osteoporosis. ${ }^{4}$ In the European Community, in the year 2000, the number of osteoporotic fractures was estimated at 3.79 million. ${ }^{3}$ The occurrence of osteoporotic fractures leads to considerable mortality, morbidity, reduced mobility and decreased quality of life. ${ }^{5}$ Moreover, future risk of osteoporotic fractures is greatly increased in patients with one or more vertebral fractures. ${ }^{6}$ In 1999, the annual number of hip fractures in 15 countries of the EC has been estimated to be 500,000 , with a total care cost of about 4.8 billion euros per year. ${ }^{7}$ In the US, in 2002 the combined annual costs of all osteoporotic fractures have been estimated to be US\$20 billion. ${ }^{8}$ This burden will further increase in absolute terms over the next years because of the aging population. ${ }^{9,8}$ Given the magnitude of the problem, the prevention and treatment of osteoporosis is, therefore, of major importance for health organizations in all countries.

The major determinant of bone strength and osteoporotic fracture risk is BMD, as assessed by dual photon absorptiometry or dual energy X-ray absorptiometry. According to World Health Organization (WHO) criteria, osteoporosis is defined to exist when BMD values fall more than 2.5 standard deviations below the young adult reference mean. ${ }^{1}$ Many studies indicate that the risk of fragility fractures increases progressively as BMD declines. ${ }^{10-13}$ It has been estimated that the risk of new vertebral fractures increases by a factor of 2.0-2.4 for each standard deviation decrease in BMD, irrespective of the site of bone density measurement. ${ }^{10}$ However, several other skeletal characteristics contribute to bone strength and interact with BMD in determining the risk of fracture. These include bone macroarchitecture (shape and geometry), bone microarchitecture (at the trabecular and cortical level), matrix and mineral composition, as well as the rate of bone turnover and the degree of mineralization or microdamage accumulation, affecting the structural and material properties of bone. ${ }^{14,15}$ The recognition and measurement of these parameters is becoming more important, and their incorporation into algorithms of fracture detection remains the subject of active research.

Osteoporosis occurs as the result of multiple mechanisms that together cause loss of bone mass and strength. ${ }^{16}$ Failure to acquire optimal bone mass and strength during growth and or an unbalance in bone remodeling leading to bone loss throughout life may all contribute to the development of the disease. In women, osteoporosis and fractures mainly occurs as a consequence of estrogen deficiency after 
menopause and results from an imbalance between bone resorption by osteoclasts and bone formation by osteoblasts, leading to a net bone loss with each remodeling cycle. A decrease in estrogen production from androgen precursors has also been supposed to be a major cause of bone loss and osteoporosis in aging men. ${ }^{17,18}$ The mechanism by which estrogen affects bone metabolism is complex and not fully elucidated. Possible mechanisms include a decrease in osteoclastogenesis, osteoclast apoptosis and additional effects on calcium homeostasis. ${ }^{19}$ Estrogen acts through the binding and activation to estrogen receptor (ER). Until recently, only one form of ER was known to exist. ${ }^{20,21}$ With the discovery of a new form of the receptor, the $\operatorname{ER} \beta,{ }^{22,23}$ encoded by a different gene, the original form has been now identified as ER $\alpha$. While both the ERs bind estrogen as well as other agonists or antagonists (although with different affinities), they have distinctly different localizations and concentrations in several tissues, including bone. ${ }^{24}$ In fact, concentrations of ER $\beta$ are higher in developing cancellous bone, whereas concentrations of $\operatorname{ER} \alpha$ are higher in developing cortical bone. ${ }^{25}$ Moreover, target cells for estrogen action may contain varying concentrations of homodimers of one or both ERs, as well as ER $\alpha$ and ER $\beta$ heterodimers. Structural functional differences also exist between $\mathrm{ER} \alpha$ and $\mathrm{ER} \beta$, when complexed with estrogen, allowing for a wide range of diverse actions to take place. ${ }^{26-28}$

In women, the decrease in estrogen production during menopause has been associated with other nonskeletal complications involving lipid metabolism, and the cardiovascular and nervous systems. Decreasing levels of estrogen have been also associated with menopausal vasomotor symptoms, such as hot flashes, insomnia, nausea, and vaginal discharge or bleeding.

\section{Current therapy options and unmet needs}

Among the several therapeutical interventions in osteoporosis, hormone replacement therapy (HRT) has traditionally been seen as the gold standard method of preventing osteoporotic fractures in postmenopausal women, as well as for the management of menopausal symptoms. Other potential benefits include the prevention of colon cancer and a neuroprotective effect. ${ }^{29}$ Despite biologically plausible mechanisms for cardiac protection by estrogen, and observational studies indicating that HRT confers cardiovascular benefit, ${ }^{30}$ the Women's Health Initiative (WHI) and other recent randomized controlled trials have failed to confirm any potential benefit in reducing the risk of coronary artery disease and stroke. ${ }^{31}$ Indeed, early increases in cardiac event and stroke rate have been seen in women taking combination HRT. Secondary analysis of the WHI trial taking into account age categories and years since menopause suggested no apparent increase in coronary hearth disease risk for women close to menopause (within 10 years of menopause and under 60 years of age), but particularly high risks in older postmenopausal women. ${ }^{32}$

Moreover, estrogen replacement, especially if administered long-term, may lead to an increased risk of breast and, when unopposed by progestins, endometrial cancers. ${ }^{33}$ Other side effects often associated with HRT are fluid retention, breast pain, headache, and resumption of menstrual cycle. These side effects may be mediated by ERs, acting on a large number of downstream signals. Thus, the use of HRT now needs to be regarded as a short-term therapy for menopausal symptom management with treatment individualized for each woman. ${ }^{34}$ In contrast, estrogen replacement must be long-term, possibly lifelong, to have any lasting impact on bone health. Alternative therapies for the prevention and the treatment of osteoporosis include bisphosphonates, calcitonin, vitamin D, selective estrogen receptor modulators (SERMs), strontium ranelate and parathyroid hormone. ${ }^{15}$ According to their mechanism of action and their prevalent effects on osteoblasts and/or osteoclasts (cells involved, respectively, in bone formation and bone resorption) all the above compounds are generally grouped into two major classes (Table 2): antiresorptive (inhibiting bone resorption) or anabolic (stimulating bone formation) agents. With this classification, antiresorptive treatments include calcium, vitamin D and its active analogs, HRT, bisphosphonates, SERMS, and calcitonin. The only available compound with a clear anabolic effect that stimulates bone formation is parathyroid hormone, either in its intact form (hPTH 1-84) or the 34 aminoacid peptide (hPTH 1-34) now called teriparatide. Strontium ranelate is considered a compound with mixed antiresorptive and anabolic activity, postulated to increase bone formation while reducing bone resorption.

The bisphosphonates (alendronate, risedronate, ibandronate, and zoledronate) are actually the most prescribed medications for the treatment of osteoporosis. Their benefits are restricted to the skeleton where they decrease the risk of vertebral and nonvertebral fractures. Moreover, adverse events such as esophagitis or esophageal ulcers, hypocalcaemia, osteonecrosis of the jaw and, concerning zoledronate, atrial fibrillation have been described in patients on bisphosphonate treatment. Even though the incidence of most of these adverse events is limited, nonadherence to and poor persistence with 
Table 2 Drugs classification for osteoporosis

Antiresorptive drugs

Bisphosphonates

Estrogens

Calcitonin

SERMs

Anabolic drugs

(Fluorides)

Teriparatide

PTH I-84

Antiresorptive and anabolic drugs

Strontium ranelate

bisphosphonates is common. ${ }^{35}$ Given its additional effects on different menopause-related complications, major efforts have been made to identify alternatives for HRT in postmenopausal women. In this respect, SERMs represent a class with a growing number of compounds that act as either ER agonists or antagonists in a tissue-specific manner. ${ }^{36,37}$ This pharmacological profile may offer the opportunity to dissociate favorable estrogenic effects on the bone from unfavorable stimulatory effects on the breast and endometrium. This class of compounds includes chemically diverse molecules that lack the steroid structure of estrogens, but possess a tertiary structure that allows them to bind to ER $\alpha$ and/or ER $\beta$. Most of the unique pharmacology of SERMs as well as their agonistic and antagonistic activity on estrogen target tissues can be explained by three main interactive mechanisms ${ }^{27}$ differential ER $\alpha$ and ER $\beta$ expression, differential ER conformation on ligand binding, and differential expression and binding to the ER of coregulator proteins (coactivators or corepressors). Because of their selective estrogen-agonist properties on different target tissues, SERMs can be indicated for the prevention or treatment of diseases caused by estrogen deficiency, including osteoporosis, without most of the undesiderable effects of estrogens. In addition, due to their selective estrogen-antagonist properties in the breast, SERMs can be also used to prevent or treat breast cancer, in which estrogen-agonistic activity is undesiderable. ${ }^{38}$

Currently there are two main chemical classes of SERMs approved for clinical use: the triphenylethylene derivatives tamoxifen and toremifene that are used to treat breast cancer, and raloxifene, a benzothiopene derivative indicated for the treatment and prevention of osteoporosis and in US for the prevention of breast cancer. ${ }^{36,37,39,40,38}$ All three also have beneficial effects on serum lipids, but are associated with venous thromboembolism and hot flushes. Moreover, although tamoxifen has a positive effect on bone as well, the increased risk of endometrial cancer eliminates it as a possible therapy for postmenopausal osteoporosis. The effects of raloxifene on bone are well established. Clinical trials demonstrated that at a daily dose of $60 \mathrm{mg}$ is effective in the prevention and treatment of postmenopausal osteoporosis and vertebral fractures. ${ }^{41-43}$ This compound also lacks estrogenic activity at the uterus but is associated with adverse effects such as blood clots and vasomotor symptoms, including hot flushes. Both preclinical and clinical reports suggest that both tamoxifen and raloxifene are considerably less potent than estrogen, ${ }^{44-46}$ in part due to their reduced bioavailability. Moreover, their effect in the prevention of hip and other nonvertebral fractures is still uncertain. The benefits of these SERMs in reducing the risks of invasive breast cancer and vertebral fracture should be weighed against the increased risks of venous thromboembolism, fatal stroke, and in case of tamoxifen, uterine cancer. A consistent number of women taking available SERMs for different indications reported moderate or severe vasomotor or gynecologic symptoms (especially vaginal dryness and hot flashes) that could hinder compliance. ${ }^{34}$ It is evident that there is a need for a SERM that has the desirable tissue-specific estrogenic and antiestrogenic actions with minimal side effects.

Newer generation SERMs being investigated for the prevention and treatment of osteoporosis in post-menopausal women include bazedoxifene, ospemifene, arzoxifene and lasofoxifene, which are in phase III clinical trials or undergoing regulatory review. ${ }^{40}$ Other new SERMS have had clinical trials suspended prematurely: levormeloxifene, for causing urinary incontinence and uterine prolapse, and idoxifene, for resulting in increased endometrial thickness on ultrasonography but without significant histological abnormality.

\section{Summary of pharmacology and preclinical evidence Mechanism of action, metabolism, and pharmacokinetic profile}

Lasofoxifene (CP-336156) is potent new generation SERM, discovered through a synthetic program aimed at isolating novel molecules with good oral bioavailability and higher potency in vivo. ${ }^{47-49}$ It is a naphthalene derivative, third generation SERM, structurally distinct from the first- and second-generation SERMs raloxifene (a benzothiopene derivative), tamoxifen and clomiphene (both triphenylethylene derivatives) or idoxifene (a pyrrolidine derivative). Lasofoxifene exerts significant estrogenic and antiestrogenic activity both in vitro and in vivo, targeting any tissues that possess ERs, such as bone, uterus, breast, blood vessels, and liver. Competitive binding assay experiments demonstrated 
high affinity of the compound for both $E R \alpha$ and $E R \beta$. Like other SERMs, lasofoxifene specifically binds to human ER $\alpha$ even though with high affinity and with a half-inhibitory concentration $\left(\mathrm{IC}_{50}\right)$ which is similar to that seen with estradiol and thus at least 10-fold higher than those reported for raloxifene, tamoxifen and droloxifene. ${ }^{47,50-52}$ Lasofoxifene also has a high affinity for the human $\operatorname{ER} \beta$ that is similar to estradiol. ${ }^{47}$

Lasofoxifene is well absorbed orally, very highly bound to plasma proteins and almost exclusively metabolized by the liver (through both oxidative and conjugative pathways), with a long elimination half-life of approximately six days (150 hours). This slow elimination is similar to some other SERMs, such as tamoxifen (120-168 hours) and toremifene (120-144 hours), but is substantially longer than for raloxifene (16-87 hours). ${ }^{53}$ However, lasofoxifene has a remarkably improved oral bioavailability with respect to other SERM compounds due to increased resistance to intestinal wall glucuronidation. This characteristic is due to its nonpolar tetrahydronaphthalene structure, making the compound a poorer substrate for glucuronidation. ${ }^{47,54}$ Conversely, the phenolic groups of benzothiopene derivatives such as raloxifene are extensively glucuronidated in the intestinal wall, which would account for their poor oral bioavailability and their limited in vivo potency. ${ }^{51-53}$ In a comparative study in the rat, lasofoxifene and raloxifene showed bioavailabilities of $62 \%$ and $10 \%$, respectively. ${ }^{47}$ In humans, both lasofoxifene and its metabolites are recovered primarily in the feces and secondarily in urine. ${ }^{55}$ Less than $2 \%$ of the administered dose of lasofoxifene is recovered unchanged in the urine; hence there is little effect in the pharmacokinetics of the drug in patients with impaired renal function.

In different studies, lasofoxifene demonstrated linear pharmacokinetics over a wide dose range (from 0.01 to $100 \mathrm{mg}) .{ }^{56,57}$ The mean time until maximum concentration $\left(\mathrm{T}_{\max }\right)$ is approximately six hours, and the estimated terminal elimination half-life (t1/2) is six days. Age, weight, race, mild to moderate hepatic or renal impairment or use of concomitant medications (ie, ketaconazole, digoxin, or warfarin) have not been associated with substantial differences in lasofoxifene pharmacokinetics. ${ }^{58-60}$ Thus, no dosage adjustment of the drug should be required for these patient-specific factors.

\section{Preclinical studies with lasofoxifene}

The effects of lasofoxifene have been tested in different in vitro cell systems as well as in different animal models. ${ }^{51-53}$ Lasofoxifene action in both skeletal and extraskeletal tissues was evaluated.
In bone cells, lasofoxifene exhibited an estrogen-like activity and, similar to estradiol, induced apoptosis of osteoclast precursors, thus decreasing bone resorption. ${ }^{61}$ Different short-term and long-term in vivo studies in ovariectomyzed (OVX) rats confirmed the in vitro evidence and demonstrated that lasofoxifene treatment (at doses of 10 to $1000 \mu \mathrm{g} / \mathrm{kg} / \mathrm{day}$ ) reduces bone turnover and is effective in protecting from OVX-induced bone loss without any major adverse finding. ${ }^{47,61-63}$ Bone histomorphometry studies of the lumbar vertebrae confirmed that the bone-protective effects of lasofoxifene were identical to those observed with estradiol, indicating that this compound is a full estrogen agonist on bone. ${ }^{61,63}$ In fact, at doses of $10-1,000 \mu \mathrm{g} / \mathrm{kg} / \mathrm{day}$ lasofoxifene completely blocked the ovariectomy-induced decrease in trabecular number and thickness as well as the increase in bone resorption indices (osteoclast number, percent osteoclast perimeter, percent eroded perimeter) and bone formation indices (labeling perimeter, BFR/BV). ${ }^{61}$ Long-term studies in the same models showed that lasofoxifene maintains its efficacy on bone over time without any major adverse finding. ${ }^{63}$ Moreover, peripheral quantitative computerized tomography analysis of proximal tibial metaphysis and biomechanical testing of the fourth lumbar vertebra clearly indicated that lasofoxifene treatment maintained bone quality and preserved bone strength in treated animals. ${ }^{63}$ Interestingly, lasofoxifene was also effective in the prevention of bone loss induced by aging or orchidectomy (ORX) in male models of osteoporosis, without significant effects on the prostate, ${ }^{64,65}$ suggesting a potential application of this compound for the treatment of osteoporosis not only in postmenopausal women but also in elderly men. A higher dose (10 to $100 \mathrm{vs} 0.01$ to $0.1 \mu \mathrm{g} / \mathrm{kg} /$ day) was required to prevent ORX-induced than age-related decrease in bone mass.

Preclinical studies demonstrated additional extraskeletal benefits of lasofoxifene on serum lipids ${ }^{47,61-66}$ as well as chemopreventive and therapeutic effects on breast cancer, comparable with those of tamoxifen. ${ }^{67,68}$ No uterine hypertrophic effects were observed at doses of 1 to $1000 \mu \mathrm{g} / \mathrm{kg} /$ day in OVX rats, ${ }^{47,63}$ and at doses of 0.1 to $100 \mu \mathrm{g} / \mathrm{kg} /$ day in immature (3-week-old) or aged (17-month-old) intact female rats. ${ }^{61}$

No toxicity was reported in the preclinical literature in either female and male rats of different ages. ${ }^{51-53}$ Importantly, at doses that efficiently prevent bone loss, lasofoxifene did not significantly affect the uterus or the prostate. Moreover, the compound did not appear to have any adverse effects on fertility in male rats. ${ }^{69}$ In female rats, lasofoxifene at different doses $(0.01,0.03$, and $1 \mathrm{mg} / \mathrm{kg} /$ day) significantly affected the oestrous cycle after 7-9 days of treatment. Restoration of 
normal estrous cycle was achieved one to two weeks after the suspension of therapy. ${ }^{70}$ As part of an International Conference on Harmonization guideline on reproductive and developmental toxicity testing for new pharmaceuticals [http://www.fda. gov/cder/guidance s5a.pdf], a pre- and post-natal study in pregnant and lactating female rats was designed. ${ }^{71}$ Lasofoxifene at oral doses of $0.01,0.03$, and $1 \mathrm{mg} / \mathrm{kg}$ decreased maternal body weight, increased dose-dependently the length of gestation and induced dystocia. Higher doses (10 or $100 \mathrm{mg} / \mathrm{kg}$ ) induced teratologic effects. ${ }^{72}$ Concentrations in maternal plasma were similar to those in milk, and increased with increasing dose, remaining consistent over a 10 day period. ${ }^{71}$ Inhibition of growth of the F1 offspring after perinatal exposure to lasofoxifene was described, without any other significant effect. No effects on the F2 generation were observed. These findings were similar to those reported for raloxifene. ${ }^{73}$

\section{Clinical evidence with lasoxoxifene in osteoporosis Clinical efficacy assessment in randomized trials}

An extensive development clinical program has been conducted with lasofoxifene, including 23 clinical pharmacology studies and 17 phase II/III clinical trials. This development program included more than 10,000 women and was designed to support the use of lasofoxifene for the prevention or treatment of postmenopausal osteoporosis (Table 3) and for the treatment of vulva-vaginal atrophy. Despite positive evidence about the skeletal efficacy of lasofoxifene have emerged from abstract presentations at different meetings, there is only a single phase II trial ${ }^{74}$ actually published in peer reviewed journals. Additional information has been derived from New Drug Application documents. ${ }^{75,76}$

Phase I studies demonstrated that lasofoxifene doses at 0.1 to $0.5 \mathrm{mg}$ after an overnight fast are well tolerated. ${ }^{56,77}$ A pharmacodynamic investigation was performed in a randomized, placebo controlled, and multiple oral dose study in 64 fasted, female volunteers. ${ }^{57}$ Included subjects were confirmed to be menopausal, within $30 \%$ of the ideal weight and without any treatment with HRT, SERM, calcitonin, sodium fluoride, and calcium supplements within the previous three months or bisphosphonates within the previous 12 months. A loading dose of five times the daily dose was followed by lasofoxifene at doses of $0.01,0.003,0.1$, 0.3 , and $1.0 \mathrm{mg} /$ day or placebo, after a fast of at least eight hours for 14 days. A tendency toward decreases in luteinizing hormone ( $\mathrm{LH})$, follicle-stimulating hormone (FSH), and low-density lipoprotein cholesterol (LDL-C) at all doses and decreases in N-telopeptide of type I collagen (NTx) at the higher doses ( 0.3 and $1.0 \mathrm{mg} /$ day) was reported. This raised the hypothesis that the dosage of $0.3 \mathrm{mg} /$ day is close to the maximally effective dose for bone markers. In subsequent phase II multiple dose studies early stage safety and efficacy of lasofoxifene was studied over a 600-fold dose range (from $0.017 \mathrm{mg} /$ day to $10 \mathrm{mg} /$ day). ${ }^{78,79}$ At all doses, the compound was well tolerated, without undue toxicity. The overall results from the dose selection analyses suggested that the lowest lasofoxifene dose necessary to achieve a fully efficacious response on BMD and LDL-C levels is $0.25 \mathrm{mg} /$ day. ${ }^{79-81}$ All lasofoxifene treatment regimens were also associated with improvements in vaginal atrophy measures, namely maturation index and vaginal $\mathrm{pH}$, compared with placebo. In a different phase II study lasofoxifene increased BMD as effectively as conjugate estrogen ('Prempro', premarin conjugated estrogen with medroxyprogesterone acetate). ${ }^{78,82,83}$

The key evidence with lasofoxifene for the treatment of osteoporosis comes from a phase II comparative trial with raloxifene and from 2 phase III trials: the Osteoporosis Prevention and Lipid Lowering (OPAL) study, and the Postmenopausal Evaluation and Risk-Reduction With Lasofoxifene (PEARL) study. All these studies assessed the disease-oriented outcomes of BMD and bone turnover markers, while only PEARL evaluated the key patient-oriented outcome of fractures.

The two-year, phase II study compared the skeletal effects of lasofoxifene $0.25 \mathrm{mg}$ /day $(\mathrm{n}=82$, mean age $59.0 \mathrm{yrs}$, average years since menopause: 10$)$ and $1.0 \mathrm{mg} /$ day $(\mathrm{n}=82$, mean age 57.7 yrs, average years since menopause: 9) to raloxifene (60 mg/day; $\mathrm{n}=163$, mean age $57.5 \mathrm{yrs}$, average years since menopause: 9$)$ and placebo $(n=83$, mean age 57.5 yrs, average years since menopause: 8 ) in 410 postmenopausal women (average T score -1.0). ${ }^{74,84,85}$ All women also received daily calcium (1000 mg) and vitamin D (250 IU) supplementation. The primary efficacy endpoint of the study was the percent change from baseline to two years in lumbar spine BMD. Secondary endpoints included total hip BMD and total body bone mineral content, the change from baseline of lumbar spine at month 6 and year 1, biochemical markers of bone turnover, LDL-C, and safety profile. At the lumbar spine, both doses of lasofoxifene significantly increased BMD compared with raloxifene and with placebo treatment $(+1.8$ and $+2.2 \%$ for 0.25 and $1.0 \mathrm{mg}$ lasofoxifene, respectively; -0.1 and $-1.7 \%$ for raloxifene and placebo, respectively; Figure 1a). ${ }^{84}$ Conversely, the two doses of lasofoxifene and raloxifene were equally effective at increasing total hip BMD. Consistent with the 
Table 3 Phase II/III trials of lasofoxifene for osteoporosis prevention or treatment

\begin{tabular}{|c|c|c|c|}
\hline Study & Design & Treatment groups & Primary endpoint \\
\hline \multicolumn{4}{|l|}{ Phase II } \\
\hline A218I037 (JADE) & Treatment & $\begin{array}{l}\text { LAS } 0.025,0.25 \text { and } \\
0.50 \mathrm{mg} / \text { day vs PB }\end{array}$ & I-year change in lumbar spine BMD \\
\hline A218I042 (LACE) & Prevention & LAS $0.25 \mathrm{mg} /$ day vs PB & 2-year change in lumbar spine BMD \\
\hline $218-101$ & Prevention & $\begin{array}{l}\text { LAS } 0.4,2.5 \text { and } \\
10 \mathrm{mg} / \text { day vs Conj. } \\
\text { Est/MPA or PB }\end{array}$ & 3-months change in bone markers \\
\hline $218-101 E$ & Prevention & $\begin{array}{l}\text { LAS } 0.4,2.5 \text { and } \\
10 \mathrm{mg} / \text { day vs Conj. } \\
\text { Est/MPA or PB }\end{array}$ & I-year change in lumbar spine BMD \\
\hline $218-102$ & Prevention & $\begin{array}{l}\text { LAS } 0.25 \text { and } \\
1.0 \mathrm{mg} / \text { day vs RAL } \\
60 \mathrm{mg} / \text { day or PB }\end{array}$ & 2-year change in lumbar spine BMD \\
\hline $218-103$ & Prevention & $\begin{array}{l}\text { LAS } 0.017,0.05,0.15 \\
\text { and } 0.50 \mathrm{mg} / \text { day vs PB }\end{array}$ & I-year change in lumbar spine BMD \\
\hline \multicolumn{4}{|l|}{ Phase III } \\
\hline A2181003/004 (OPAL) & Prevention & $\begin{array}{l}\text { LAS } 0.025,0.25 \text { and } \\
0.50 \mathrm{mg} / \text { day vs PB }\end{array}$ & 2-year change in lumbar spine BMD \\
\hline A2। 81002 (PEARL) & Treatment & $\begin{array}{l}\text { LAS } 0.25 \text { and } \\
0.50 \mathrm{mg} / \text { day vs PB }\end{array}$ & $\begin{array}{l}\text { New/worsening radiographic vertebral } \\
\text { fracture }\end{array}$ \\
\hline A2181030 (CORAL) & Prevention & $\begin{array}{l}\text { LAS } 0.25 \mathrm{mg} / \text { day vs RAL } \\
60 \mathrm{mg} / \text { day or PB }\end{array}$ & $\begin{array}{l}\text { Change in lumbar spine BMD and } \\
\text { percent of BMD response after 2-years }\end{array}$ \\
\hline
\end{tabular}

Abbreviations: BMD, bone mineral density; Est, estrogen; LAS, lasofoxifene; MPA, medroxyprogesterone acetate; PB, placebo; RAL, raloxifene.

effects on BMD, biochemical markers of bone turnover (urinary $\mathrm{N}$-telopeptide and deoxypyridinoline crosslinks, serum bone-specific alkaline phosphatase and osteocalcin) significantly decreased after two years of lasofoxifene treatment with respect to placebo. No major differences were observed between the $0.25 \mathrm{mg}$ and $1.0 \mathrm{mg}$ lasofoxifene groups. Overall, the effects on bone turnover were similar or greater than those observed with raloxifene. At two years, both doses of lasofoxifene resulted in greater reductions in LDL-C and total cholesterol levels when compared with raloxifene and placebo. ${ }^{85}$ Moreover lasofoxifene-treated women showed significantly greater decreases in Apo B100 (-11.7\% vs $-5 \%)$ and lipoprotein(a) $(-37.7 \%$ vs $-25.6 \%)$ and significantly greater increase in Apo A1 (+5.5\% vs 1.6\%) compared with raloxifene-treated women. Lasofoxifene was also effective in reducing levels of coagulation factors (fibrinogen, plasminogen activator inhibitor-1 [PAI-1], and antithrombin III activity) compared with placebo ( $\mathrm{p}<0.05$ ). No differences in breast pain were observed with lasofoxifene compared to placebo or raloxifene.

Pooled preliminary results from the OPAL studies have been only presented in abstract form. ${ }^{86,87}$ These were two identical phase III, 24-month, prospective, multicenter, randomized, double-blind, placebo-controlled, parallel-group trials in 1907 healthy postmenopausal women aged 40 to 75 years ( 3 to 20 years postmenopausal). Among the inclusion criteria there was a lumbar spine BMD T score between 0 and -2.5 . Women were excluded if they had diseases associated with altered bone metabolism, malignancy within the previous five years, ovarian or uterine pathology, spinal deformities that would affect lumbar densitometry, hip prosthesis, or a history of nontraumatic vertebral or hip fractures. Following a six to eight week placebo run-in period, recruited subjects were randomized 1:1:1:1 to receive 24 months of doubleblind treatment with lasofoxifene $0.025 \mathrm{mg} /$ day, $0.25 \mathrm{mg} /$ day, and $0.5 \mathrm{mg} /$ day or placebo. All patients received calcium or vitamin D supplementation. The primary endpoint was the two-year change in lumbar spine BMD, which was evaluated using an a priori fixed sequence multiple comparisons procedure on data pooled from both studies.

Lasofoxifene treatment significantly increased BMD and decreased bone turnover compared to placebo, with beneficial changes observed as early as six months. ${ }^{86}$ All three lasofoxifene doses were able to significantly increase lumbar and femoral BMD at 6, 12, and 24 months as compared with a decrease observed in calcium and vitamin D supplemented placebo group. At two years, lumbar BMD increased by $1.5 \%, 2.3 \%$, and $2.3 \%$ in lasofoxifene 
$0.025 \mathrm{mg} /$ day, $0.25 \mathrm{mg} /$ day, and $0.5 \mathrm{mg} /$ day treatment groups, respectively, as compared with a decrease of $0.7 \%$ with placebo (Figure 1b). A significant decrease in bone turnover markers (osteocalcin, CTX, and P1NP) was also observed at six and 24 months in lasofoxifene treatment groups with respect to placebo. Moreover, bone biopsies in lasofoxifene-treated subjects showed bone of normal quality. Changes in signs and self-assessed symptoms of vaginal atrophy or cognitive function and variations in lipid levels were also periodically analyzed over 24 months. ${ }^{87}$ Neither breast density, assessed by mammography in 351 women, nor breast pain increased in the lasofoxifene groups. There was a significant improvement in vaginal $\mathrm{pH}$ at 12 and 24 months for all doses of lasofoxifene versus placebo. The assessment of the degree of vaginal maturation indicated significantly lower percentages of parabasal cells and significantly higher proportions of intermediate and superficial cells at 12 and 24 months in lasofoxifene-treated women with respect to placebo. The evaluation of cognitive function and mood in a subset of patients $(n=267)$ did not show any difference between lasofoxifene and placebo groups, except a lower CESD-10 depression score at 12 months and a lower Digits Forward score in $0.025 \mathrm{mg}$ group; neither results were judged to be clinically meaningful. At all time points lasofoxifene treatment was associated with significant reductions in LDL-C relative to placebo. LDL-C reductions were significantly greater in the 0.25 and $0.5 \mathrm{mg}$ /day groups than in the $0.025 \mathrm{mg} /$ day group. Similar reductions were observed in total cholesterol, high density lipoprotein cholesterol (HDL-C), total cholesterol/HDL-C ratio, apolipoprotein
B100, apolipoprotein B100/apolipoprotein A1 ratio, and lipoprotein $\mathrm{a}$, in all treatment groups. Relative to placebo, lasofoxifene 0.25 and $0.5 \mathrm{mg} /$ day were associated with small but significant increases in tryglicerides from baseline at all time points. At 24 months, all lasofoxifene treatment groups were associated with significantly greater reductions in the prothrombotic marker fibrinogen and high sensitivity C-reactive protein compared with placebo.

The PEARL trial was a randomized, double-blind, placebo-controlled, parallel assignment study aimed to determine the safety and effectiveness of two doses of lasofoxifene in reducing the risk of new/worsening radiographic spinal fractures (primary endpoint) in women with osteoporosis; ${ }^{78}$ http://www.clinicaltrials.gov/ct]. Secondary outcomes included nonvertebral fractures, BMD, bone markers, breast cancer, cardiovascular events, and gynecological safety events. Osteoporotic postmenopausal women ( $\mathrm{n}=8556$, BMD T score $<-2.5 \mathrm{SD}$, age range $59-80 \mathrm{yrs}$ ) were included in the study if they had no other metabolic bone disease, if they were not taking medications approved for osteoporosis, if they have had no recent fracture (within one year), no more than three prevalent vertebral fractures on baseline X-ray and/or a $\mathrm{BMD}<-4.5 \mathrm{SD}$ at the lumbar spine or the femoral neck. The study was originally designed as a three-year study, but was extended by two additional years via a protocol amendment in order to provide long-term exposure data.

Results have been recently released in abstract form, ${ }^{88-90}$ as well as in two additional documents [http://www.fda. gov/ohrms/dockets], but have not yet been published in peer-reviewed papers.
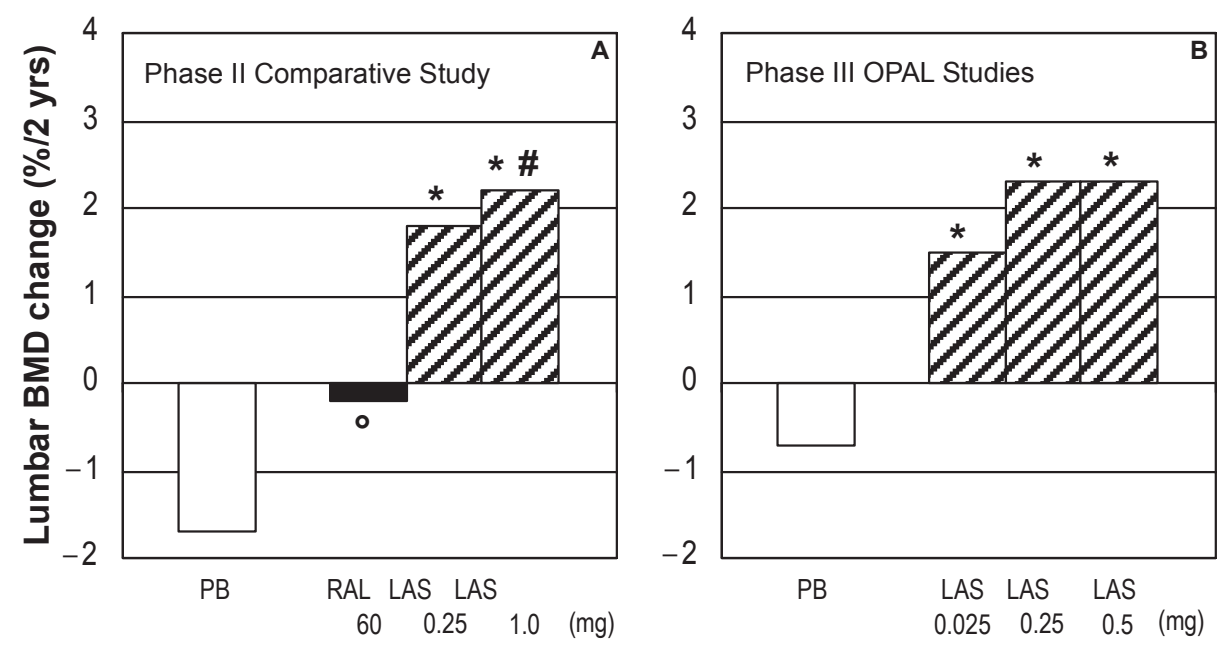

${ }^{*} p<0.001$ LAS vs PB; ${ }^{\circ} p<0.01$ RAL vs PB; ${ }^{*} p<0.05$ LAS vs RAL

Figure I Effects of lasofoxifene on lumbar BMD (\% change at two years) (A) in a phase II comparison to raloxifene or placebo and (B) in phase III OPAL studies. Abbreviations: BMD, bone mineral density; LAS, lasofoxifene; RAL, raloxifene; PB, placebo. 
At three years, lasofoxifene significantly reduced bone turnover markers and improved BMD at the spine $(3.3 \%$ for both doses; $\mathrm{p}<0.001)$ and femoral neck $(2.7 \%$ for $0.25 \mathrm{mg}$ and $3.3 \%$ for $0.5 \mathrm{mg} ; \mathrm{p}<0.001$ ), compared with placebo. A significant reduction in vertebral fracture risk was demonstrated with both treatment arms (31\% for $0.25 \mathrm{mg}$; $\mathrm{p}=0.002$ and $42 \%$ for $0.5 \mathrm{mg} ; \mathrm{p}<0.001$ ) (Figure 2). This effect was observed as early as one year for both doses of lasofoxifene and was sustained through five years. A similar risk reduction was observed with both doses in women with or without prevalent fracture at baseline. The risk of nonvertebral fractures at three years was significantly reduced by $22 \%(p=0.02)$ in the lasofoxifene $0.5 \mathrm{mg}$ group and was maintained through five years (Figure 3 ). Consistent with the data on vertebral fractures, the significant effect of lasofoxifene $0.5 \mathrm{mg}$ on nonvertebral fractures was observed as early as one year. Conversely, lasofoxifene $0.25 \mathrm{mg}$ did not significantly reduce nonvertebral fracture risk at any time point. Of interest, lasofoxifene $0.25 \mathrm{mg}$ and $0.5 \mathrm{mg}$ also reduced the risk of ER-positive breast cancer (by 84\% and $67 \%$, respectively) and of all breast cancers (Figure 4). This effect was maintained $(79 \%$ reduction of all breast cancers) after five years with lasofoxifene $0.5 \mathrm{mg}$. Efficacy of lasofoxifene treatment on vulvar and vaginal atrophy endpoints (symptoms, vaginal $\mathrm{pH}$ and maturation index, percentage of parabasal cells and of superficial cells) was also demonstrated with both lasofoxifene doses.

\section{Safety and tolerability}

In all clinical trials performed to date, lasofoxifene appeared to be well tolerated. ${ }^{56,77,78,87}$ In general, adverse events were mild or moderate and usually resolved within a few days, without treatment discontinuation. Moreover, there were no changes in adverse event frequency or intensity with increasing dose. In a comparative phase II study, the adverse event profile of lasofoxifene was similar to that of raloxifene with respect to increases in hot flashes and leg cramps compared with placebo. ${ }^{84}$ These appear to be class effects of SERMs. ${ }^{91}$ An increased frequency of urogenital symptoms (mainly increased vaginal moisture, considered to be beneficial by some women) were observed in lasofoxifene-treated groups compared with the raloxifene-treated group. ${ }^{84}$ This is consistent with preclinical observations showing that lasofoxifene stimulates vaginal mucus formation without causing cell proliferation in the rat reproductive tract. ${ }^{92}$ Vasodilatation was an additional adverse event attributed to lasofoxifene treatment in another one-year study on healthy postmenopausal women. ${ }^{80}$ In phase III studies adverse events reported by more than $5 \%$ of lasofoxifene treated subjects included hot flashes, leg cramps and increased vaginal moisture. ${ }^{87,90}$

Major general safety events of special interest for any SERM have been comprehensively addressed in phase III clinical trials, as secondary endpoints. There were two safety findings of note associated with lasofoxifene treatment: an increased incidence of uterine diagnostic procedures and an increase in venous thromboembolic events. Even though the larger clinical safety database from the PEARL trial does not show evidence of an increased risk of endometrial cancer or hyperplasia associated with the use of lasofoxifene for five years, gynecologic adverse events occurred more frequently than placebo; ${ }^{90}$ http://www.clinicaltrials. gov/ct]. These included uterine polyps and endometrial hypertrophy, both considered benign findings, as well as an increased reporting of uterine prolapse. The latter was not confirmed by comprehensive and specific rating scales used to evaluate pelvic organ prolapse, nor was there a significant increase in prolapse surgery through five years of follow-up in the PEARL trial. Benign effects on the endometrium were characterized by an approximate $1.5 \mathrm{~mm}$ mean increase in endometrial thickness and increased cystic echotexture on ultrasound, which are consistent with benign cystic atrophy on biopsy. These effects have been attributed to increased vascular permeability by lasofoxifene, which results in uterine imbibition and accumulation of fluid in both the glands and stroma of the endometrium, consistent with the cystic echotexture and increased endometrial thickness observed on ultrasound, together with the benign cystic atrophy observed on biopsy. In the PEARL study, vaginal bleeding was reported with low frequency, but was more common in lasofoxifene-treated patients compared to placebo. This small increase in vaginal bleeding, together with asymptomatic benign endometrial findings detected in unplanned transvaginal ultrasound, contributed to the observed increase in diagnostic uterine procedures. During the five years follow up of the PEARL study, lasofoxifene was associated with an approximate twofold increased risk of venous thromboembolism, mainly driven by an increased risk of deep vein thrombosis. ${ }^{90}$ In fact, pulmonary embolism occurred less frequently than deep vein thrombosis $(0.2 \%$ vs $0.8 \%$, respectively) but was also significantly increased in lasofoxifenetreated patients compared to placebo (hazard ratio [HR] 4.49, 95\% confidence interval [CI]: 0.97-20.79 for lasofoxifene $0.5 \mathrm{mg}$ and HR 5.98, 95\% CI: 1.33-26.72 for lasofoxifene $0.25 \mathrm{mg}$ ). Conversely, lasofoxifene was not associated with an increased risk of stroke. Indeed, while the prospectivelydefined analysis included transient ischemic attacks (TIAs), 


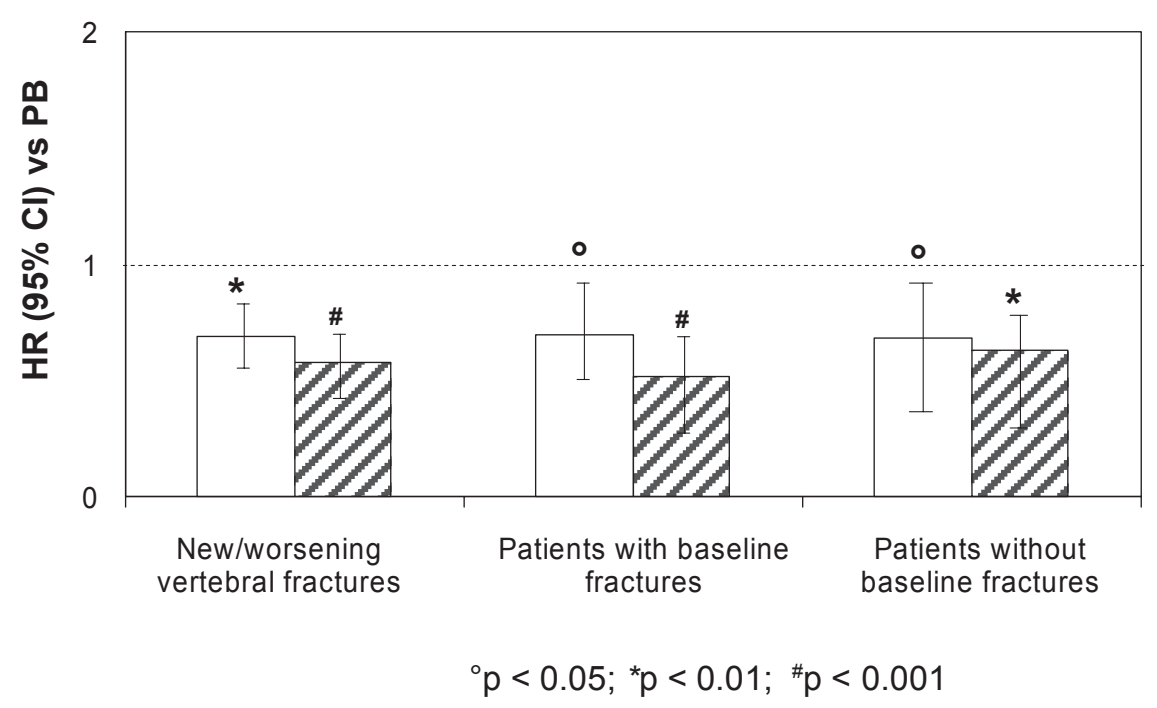

Figure 2 Reduction in the risk (HR) for new/worsening radiographic vertebral fractures after three years of lasofoxifene $(0.25$ and $0.50 \mathrm{mg} /$ day) treatment compared with placebo: the PEARL study.

Abbreviations: $\mathrm{Cl}$, confidence interval; $\mathrm{HR}$, hazard ratio; $\mathrm{PB}$, placebo.

an analysis excluding TIAs showed lasofoxifene to be associated with a decreased risk of stroke.

Consistent with preclinical data, both three- and five-year data from the PEARL study clearly showed that lasofoxifene treatment is associated with a reduction in risk of breast cancer (this was a co-primary endpoint in the PEARL study at five years). This effect was evident with lasofoxifene $0.5 \mathrm{mg}$ for all breast cancers, ER+, invasive, and ER+ invasive breast cancers which was not consistently observed with lasofoxifene $0.25 \mathrm{mg}$ [http://www.clinicaltrials.gov/ct].

Importantly, lasofoxifene $0.5 \mathrm{mg}$ was associated with a significant $32 \%$ reduction in major coronary events (including coronary death, nonfatal myocardial infarctions, coronary revascularization procedures, documented new ischemic heart disease, and hospitalizations for unstable angina) through five years [http://www.clinicaltrials.gov/ct]. Markers of cardiovascular risk (total cholesterol, LDL-cholesterol, and high sensitivity C-reactive protein) were measured at three years and showed a significant reduction in lasofoxifene-treated subjects compared to placebo.

\section{Economic evidence}

Pharmacoeconomic evaluation on the use of lasofoxifene in osteoporosis prevention or treatment has been not released. Moreover, although several articles addressed the economic value of specific agents, the cost-effectiveness of all currently available drugs approved for the treatment of osteoporosis has not been reported. Antiresorptive agents are considered effective in reducing fracture incidence and generally have favorable cost-effectiveness profiles for most postmenopausal women with osteoporosis. ${ }^{93,94}$ Recent results from the US further support the treatment of high risk postmenopausal populations because of the gain in quality-adjusted life years (QALYs) and, in women aged 75 years with previous fracture, overall cost savings because of the reduction in health care services. ${ }^{95}$ The WHO recently developed a clinical tool for calculation of the 10-year probability of fracture, that can be used in combination with country specific data (ie, fracture rates, health care costs) to develop cost-effective intervention thresholds for osteoporosis treatment. Using US-specific data, the cost-effectiveness for treatment is reached when the 10-year probability of hip fracture using the WHO algorithm is approximately $3 \%$ or above. ${ }^{96}$

To date, few studies have considered the favorable extraskeletal effects of SERMs or the impact of drug side effects on the cost-effectiveness of treatment. In this context, it is important to differentiate between the quality of life impact caused by the antifracture efficacy of an intervention and any general quality of life impact that it may have independently of that antifracture efficacy. In a UK meta-analysis considering postmenopausal women unselected for low BMD and modeled for additional conditions such as breast cancer and cardiovascular health, only raloxifene proved cost-effective for the prevention of vertebral fractures at 60 years of age, with a cost per QALY of $£ 26,000$ (assuming no impact on hip fractures) that was 
Lasofoxifene $0.25 \mathrm{mg}$ Lasofoxifene $0.50 \mathrm{mg}$

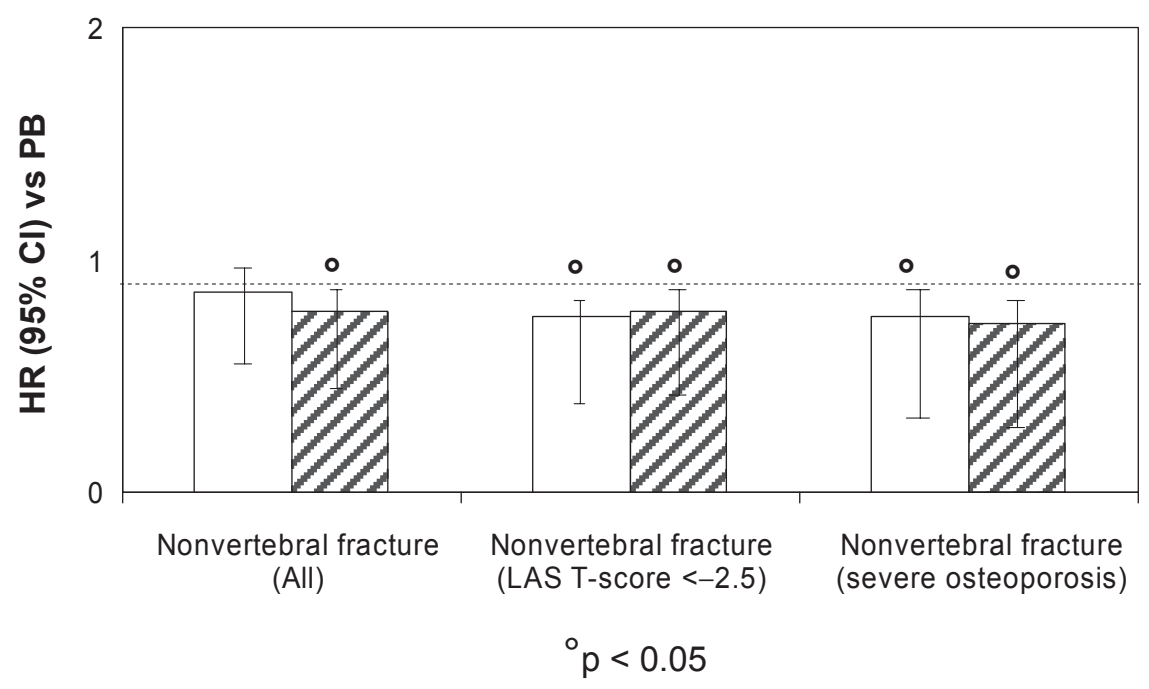

Figure 3 Reduction in the risk (HR) for nonvertebral fractures after three years of lasofoxifene $(0.25$ and $0.50 \mathrm{mg} /$ day $)$ treatment, compared with placebo: the PEARL study. Abbreviations: $\mathrm{Cl}$, confidence interval; $\mathrm{HR}$, hazard ratio; $\mathrm{LAS}$, lasofoxifine; $\mathrm{PB}$, placebo.

below the estimated threshold of $£ 35,000$ corresponding to no treatment (with the assumption that all women had sufficient intakes of calcium and vitamin D). ${ }^{97}$ Bisphosphonates such as alendronate, etidronate, and risedronate had a cost per QALY above that threshold. Moreover, none of the considered interventions was shown to cost-effectively reduce the risk of nonvertebral fractures in women unselected for low BMD. These net costs were markedly different by age, with some treatment regimens becoming cost-saving at higher age-ranges in patients with a prior fracture.

Long-term phase II studies and the recent results from the PEARL phase III trial show that lasofoxifene has an improved profile in bone parameters (ie, markers of bone resorption and BMD) with significant improvement in fracture prevention (particularly in nonvertebral fractures) over the current leading SERM, raloxifene. This new SERM also retains a similar positive effect in breast cancer prevention to raloxifene, with potentially improved cardiovascular benefits. Thus if lasofoxifene will be marketed at a similar cost to current products its cost-effectiveness should be improved with respect to raloxifene.

\section{Patient group/population}

Preliminary evidence from randomized phase III clinical trials, released in abstract form, has shown vertebral and nonvertebral fracture risk reduction with lasofoxifene $0.5 \mathrm{mg} /$ day in postmenopausal women with postmenopausal osteoporosis with or without a previous fracture.
Potential additive beneficial effects of treatment include vaginal atrophy, breast cancer prevention and heart disease. Confirmation of such positive results in these areas would make the drug very attractive to patients at risk for those conditions and postmenopausal bone loss, vastly extending the drug's patient potential. Some concerns on the overall risk/benefit profile of lasofoxifene are related to the slight increase in the number of deaths observed at five years in the PEARL study in subjects treated with lasofoxifene $0.25 \mathrm{mg} /$ day versus placebo (90 vs 65, respectively). Moreover, because treatment with lasofoxifene, similar to other SERM compounds, is associated with hot flushes, deep venous thromboses, pulmonary embolism, and leg cramps, patients taking this SERM should be informed of these adverse events. Potential increased risk of vaginal bleeding, mainly due to uterine polyps, should be also reported in the lasofoxifene drug product label.

\section{Dosage, administration, and formulations}

According to the recent NDA application (22-242), and based on the improved clinical efficacy on bone and extraskeletal endpoints of lasofoxifene $0.5 \mathrm{mg}$ versus $0.25 \mathrm{mg}$, the compound will be supplied as $0.5 \mathrm{mg}$, film-coated tablets (lasofoxifene tartrate $0.5 \mathrm{mg}$; Fablyn ${ }^{\circledR}$, Ligand Pharmaceuticals Inc./Pfizer Inc.) for daily oral administration. Initial pharmacokinetic studies demonstrated that food does not significantly affect the bioavailability of single doses of 
lasofoxifene relative to the fasting state. ${ }^{77}$ Therefore the drug can be dosed without regard to the timing of meals.

\section{Place in therapy for lasofoxifene in osteoporosis}

During the past 10 years, several efforts have been devoted to the understanding of ER system and the development of compounds that interact with intracellular ERs in target organs as estrogen agonist and antagonists. The search for a SERM molecule with an ideal pharmacologic profile, which has estrogen-like activity on the bone and the lipid profile, antiestrogenic activity on the breast and neutral activity on the uterus, represented for many years the goal to be achieved by pharmaceutical companies. This need has been further emphasized by the recent negative results from WHI and other randomized controlled trials on HRT, ${ }^{31}$ particularly for long-term treatment regimens in late postmenopausal women. ${ }^{32}$ Thus far, a very versatile group of SERMs have been developed, with potentially different indications and different compounds are actually under investigation. However, although currently available SERMs possess many benefits, they are also responsible for some very serious side effects, such as thromboembolic disorders and uterine cancer. These contraindications represent a major concern for the type of long-term, chronic therapy that is required to prevent osteoporosis. Moreover, a consistent proportion of women taking available SERMs for different indications reported moderate or severe vasomotor or gynecologic symptoms (especially vaginal dryness and hot flashes) that could hinder compliance. These side effects have been also reported for most of the new SERMs under development, including arzoxifene, droloxifene and idoxifene, as well as for raloxifene, the only SERM compound actually approved worldwide for the prevention and treatment of osteoporosis. Moreover, both preclinical and clinical reports suggest that these SERMs are considerably less potent than estrogen, probably due to their reduced bioavailability. ${ }^{44-46}$

In this context, lasofoxifene appears to be a promising new SERM for the prevention and treatment of osteoporosis. Due to increased resistance to intestinal wall glucuronidation, this compound has shown a remarkably improved oral bioavailability and increased in vitro and in vivo potency with respect to other SERMs. Moreover, lasofoxifene shows a beneficial pharmacologic profile on bone, breast, and serum lipids, without any major adverse effects on the uterus. In fact, even though there was an increased percentage of patients reporting endometrial polyps and vaginal bleeding leading to more gynecologic procedures during lasofoxifene treatment, there is no evidence of increase endometrial carcinoma or endometrial hyperplasia in the lasofoxifene treated-women compared to placebo. Interestingly, the chemopreventive and therapeutic effects of lasofoxifene on animal models of breast cancer appear higher than those of raloxifene, and comparable with those of tamoxifen. Potential additional benefits that lasofoxifene may have over raloxifene include its beneficial estrogen-like effects on urogenital

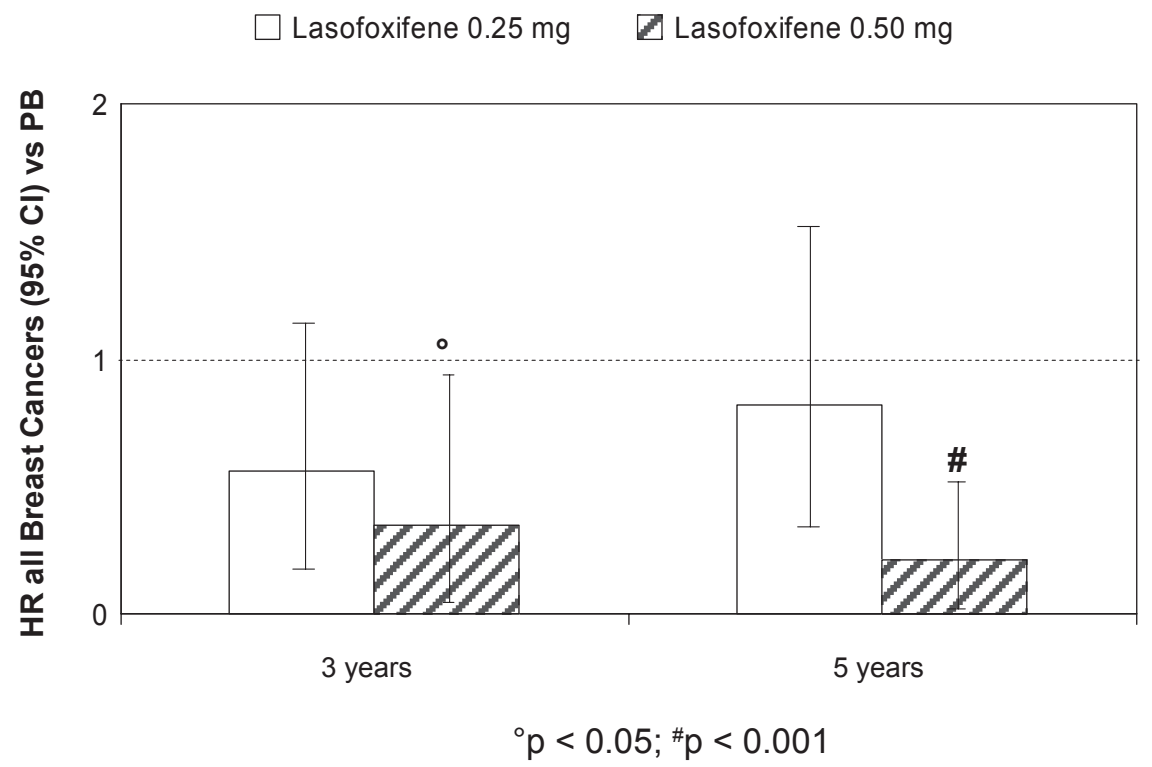

Figure 4 Effects of lasofoxifene treatment $(0.25$ and $0.50 \mathrm{mg})$ on breast cancer risk reduction at three and five years: the PEARL study. Abbreviations: $\mathrm{Cl}$, confidence interval; $\mathrm{HR}$, hazard ratio; $\mathrm{PB}$, placebo. 
atrophy. This latter issue has been recently addressed in planned interim analysis from a placebo-controlled trial on postmenopausal women ${ }^{78}$ and might represent an important benefit since about $40 \%$ of women, potential users of SERMs, report vaginal dryness and other complications associated with urogenital atrophy (ie, vaginal discharge and infections, recurrent urinary tract infections, and dyspareunia).

In 2004, following the positive results of phase II/III studies on postmenopausal women, Pfizer decided to submit two new drug applications (NDA) to the US Food and Drug Administration (FDA) for lasofoxifene $0.25 \mathrm{mg}$ for the prevention of osteoporosis in postmenopausal women (NDA 21-757) and for the treatment of moderate to severe symptoms of vaginal atrophy in postmenopausal women with low bone mass (NDA 21-843). In not-approvable letters issued in 2005 for osteoporosis prevention and 2006 for treatment of vaginal atrophy, the FDA acknowledged that efficacy had been demonstrated for both indications, but stated concerns regarding a hypothetical risk of endometrial cancer and an increased risk of invasive gynecological procedures. Based on the positive results of the long term (three years), phase III, fracture trial PEARL and of the two-year extension on safety concerns, a new application (NDA 22-242) has been recently submitted to request approval of Fabyln ${ }^{\circledR}$ (lasofoxifene tartrate, $0.5 \mathrm{mg}$ tablets) for the treatment of osteoporosis in postmenopausal women at increased risk of fracture.

Due to the reporting out of PEARL at five years, the lasofoxifene safety database at the time of this NDA submission for the treatment of osteoporosis was about seven times larger than that provided in the previously submitted NDAs.

The available results from PEARL demonstrate that lasofoxifene $0.5 \mathrm{mg}$ significantly reduced the risk of new/worsening radiographic vertebral fracture, the risk of nonvertebral fracture, and the risk of clinical fracture in postmenopausal women with osteoporosis. Significant risk reduction for these parameters was seen as early as one year and was sustained through five years of treatment. Overall, these results on skeletal outcomes are consistent with preclinical or preliminary phase II comparative observations $^{74}$ and indicate an improved efficacy of lasofoxifene over raloxifene. Additionally, lasofoxifene $0.5 \mathrm{mg}$ seemed to exert comparable clinical efficacy in reducing the risk of breast cancer (ER+, all, ER+ invasive, and invasive) than raloxifene, with a risk reduction that was equivalent to that observed in the MORE and CORE trials. ${ }^{98,99}$ Moreover, the recent enlargement of the safety database with the inclusion of five-year results from the extension of the PEARL trial has allowed a more robust assessment of the benefit-risk profile of lasofoxifene for the treatment of osteoporosis in postmenopausal women and has enabled Pfizer to address the specific concerns on gynecological safety previously raised by the FDA. Despite a twofold greater number of women within each lasofoxifene group ( 0.25 and $0.5 \mathrm{mg})$ that underwent one or more uterine procedures than in placebo group, there was no evidence of a clinically significant increase in the incidence of uterine cancer or endometrial hyperplasia over the five years of treatment. An increased number of patients with vaginal bleeding, along with increased endometrial thickness and increased endometrial polyps, appeared as the major causes leading to more gynecologic procedures in lasofoxifene treated subjects. Even though of less clinical significance than endometrial cancer, these adverse events might impact the overall risk-benefit profile of the compound. Other additional concerns of lasofoxifene treatment are the increased percentage of subjects with venous thromboembolic events (largely due to deep vein thrombosis) and a slightly increased percentage of all-cause mortality on both the three- and five-year safety data compared with placebo. Unexpectedly, the percentage of subjects who died in the $0.25 \mathrm{mg}$ lasofoxifene group exceeded that in the $0.5 \mathrm{mg}$ group and was statistically greater than that in the placebotreated subjects based on five-year data. The excess numbers of deaths were found primarily in the noncoronary vascular and cancer categories. The latter did not appear to be focused in any specific organ system. Slightly more cancer deaths occurred in the brain, lung, and gastrointestinal system in the lasofoxifene-treated subjects. The impact of these findings on the overall risk/benefit profile of lasofoxifene for the proposed indication remains unclear and needs further investigation.

In addition to the improved efficiency on the prevention of vertebral fractures and to the significant effect on the prevention of nonvertebral fractures (that was not demonstrated with raloxifene) additional benefits of lasofoxifene over currently available SERMs are the beneficial effects on urogenital atrophy and the cardiovascular system. Confirmation of such positive results in these areas would make the drug very attractive to patients at-risk for those conditions and postmenopausal bone loss, vastly extending the drug's patient potential. No information at all is available addressing the pharmacoeconomic aspects of a treatment with lasofoxifene.

In conclusion, consistent with the encouraging preclinical evidence, the recently presented results from PEARL trial indicate that lasofoxifene may represent a valid alternative to HRT or raloxifene in the treatment of 
postmenopausal osteoporosis. Specific studies on different outcomes (ie, the prevention of breast cancer or coronary events in high-risk populations) and longer term analysis in larger samples concerning clinically relevant adverse events will be needed to obtain a reasonable view of the future and cost-effectiveness of this compound in the management of women's health following menopause.

\section{Disclosure}

The authors report no conflicts of interest in this work.

\section{References}

1. Anon. Osteoporosis Prevention, Diagnosis, and Therapy Consensus Statement 2000. JAMA. 2001;285:785-795.

2. Melton LJ 3rd, Chrischilles EA, Cooper C, Lane AW, Riggs BL. Perspective. How many women have osteoporosis? J Bone Miner Res. 1992;7:1005-1010.

3. Reginster JY, Burlet N. Osteoporosis: a still increasing prevalence. Bone. 2006;38:S4-S9.

4. Riggs BL, Melton III LJ. The worldwide problem of osteoporosis: insights afforded by epidemiology. Bone. 1995;17(5 Suppl):505S-511S.

5. Barrett-Connor E. The economic and human costs of osteoporotic fracture. Am J Med. 1995;98:3S-8S.

6. Melton LJ, Atkinson EJ, Cooper C, O'Fallon WM, Riggs BL. Vertebral fractures predict subsequent fracture. Osteoporos Int. 1999;10:214-221.

7. Anon. International Osteoporosis Foundation 1999. Survey by Helmut Minne, November 1999.

8. Cummings SR, Melton LJ III. Epidemiology and outcomes of osteoporotic fractures. Lancet. 2002;359:1761-1767.

9. Cooper C, Campion G, Melton III LJ. Hip fractures in the elderly: a world-wide projection. Osteoporos Int. 1992;2:285-289.

10. Black DM, Cummings SR, Genant HK, Nevitt MC, Palermo L, Browner W. Axial and appendicular bone density predict fractures in older women. J Bone Miner Res. 1992;7:633-638.

11. Cummings SR, Black DM, Nevitt MC, et al. Appendicular bone density and age predict hip fracture in women: the study of Osteoporotic Fractures Research Group. JAMA. 1990;263:665-668.

12. Cummings SR, Black DM, Nevitt MC, et al. Bone density at various sites for prediction of hip fractures. Lancet. 1993;341:72-75.

13. Hui SL, Slemenda CW, Carey MA, Johnston CC. Choosing between predictors of fractures. J Bone Miner Res. 1995;10:1816-1822.

14. Seeman E, Delmas PD. Bone quality - the material and structural basis of bone strength and fragility. N Engl J Med. 2006;354:2250-2261.

15. Sambrook P, Cooper C. Osteoporosis. Lancet. 2006;367:2010-2018. Erratum: Lancet. 2006;368:28.

16. Raisz LG. Pathogenesis of osteoporosis: concepts, conflicts and prospects. J Clin Invest. 2005;115:3318-3325.

17. Khosla S, Melton LJ III, Riggs BL. Clinical review 144: Estrogen and the male skeleton. J Clin Endocrinol Metab. 2002;87:1443-1450.

18. Gennari L, Khosla S, Bilezikian JP. Estrogen and fracture risk in men. J Bone Miner Res. 2008;23:1548-1551.

19. Riggs BL, Khosla S, Melton LJ III. Sex steroids and the construction and conservation of the adult skeleton. Endo Rev. 2002;23:279-302.

20. Green S, Walter P, Kumar V, Bornet J, Arpos P, Chambon P. Human estrogen receptor cDNA: sequence, expression and homology to v-erb-A. Nature. 1986;320:134-139.

21. Greene P, Gilna M, Waterfield A, Baker Y, Hort J, Shine, Sequence and expression of human estrogen receptor complementary DNA. Science. 1986;231:1150-1154.

22. Kuiper GGJM, Enmark E, Pelto-Huikko M, Nilsson S, Gustafsson JA. Cloning of a novel estrogen receptor expressed in rat prostate and ovary. Proc Natl Acad Sci U S A. 1996;93:5925-5930.
23. Mosselman S, Polman J, Dijkema R. ER beta: identification and characterization of a novel human estrogen receptor. FEBS Lett. 1996;392:49-53.

24. Gustafsson JA. Estrogen receptor beta-a new dimension in estrogen mechanism of action. J Endocrinol. 1999;163:379-383.

25. Bord S, Horner A, Beavan S, Compston J. Estrogen receptors alpha and beta are differentially expressed in developing human bone. J Clin Endocrinol Metab. 2001;86:2309-2314.

26. Ogawa $\mathrm{S}$, Inoue $\mathrm{S}$, Watanabe $\mathrm{T}$, et al. The complete primary structure of human estrogen receptor beta (hER beta) and its heterodimerization with ER alpha in vivo and in vitro. Biochem Biophys Res Commun. 1998;243:122-126.

27. Riggs BL, Hartmann LC. Selective estrogen-receptor modulatorsmechanisms of action and application to clinical practice. $N$ Engl $J$ Med. 2003;348:618-629.

28. Pike AC. Lessons learnt from structural studies of the oestrogen receptor. Best Pract Res Clin Endocrinol Metab. 2006;20:1-14.

29. Chlebowski RT, Wactawski-Wende J, Ritenbaugh C, et al. Women's Health Initiative Investigators. Estrogen plus progestin and colorectal cancer in postmenopausal women. $N$ Engl J Med. 2004;350:991-1004.

30. Grodstein F, Manson JE, Colditz GA, Willett WC, Speizer FE, Stampfer MJ. A prospective, observational study of postmenopausal hormone therapy and primary prevention of cardiovascular disease. Ann Intern Med. 2000;133:933-941.

31. Manson JE, Hsia J, Johnson KC, et al. Women's Health Initiative Investigators. Estrogen plus progestin and the risk of coronary heart disease. N Engl J Med. 2003;349:523-534.

32. Rossouw JE, Prentice RL, Manson JE, et al. Postmenopausal hormone therapy and risk of cardiovascular disease by age and years since menopause. JAMA. 2007;297:1465-1477.

33. Vassilopoulou-Sellin R. Breast cancer and hormonal replacement therapy. Ann N Y Acad Sci. 2003;997:341-350.

34. Anon. HRT: what are women (and their doctors) to do? Lancet. 2004;364:2069-2070.

35. Rabenda V, Mertens R, Fabri V, et al. Adherence to bisphosphonates therapy and hip fracture risk in osteoporotic women. Osteoporos Int. 2008; 19:811-818.

36. Cho CH, Nuttall ME. Therapeutic potential of oestrogen receptor ligands in development for osteoporosis. Emerg Drugs. 2001;6:137-154.

37. Nilsson S, Koehler KF. Oestrogen receptors and selective oestrogen receptor modulators: molecular and cellular pharmacology. Basic Clin Pharmacol Toxicol. 2005;96:15-25.

38. Gennari L, Merlotti D, De Paola V, Nuti R. Raloxifene in breast cancer prevention. Expert Opin Drug Saf. 2008;7:259-270.

39. Morello KC, Wurz GT, DeGregorio MW: SERMs: current status and future trends. Crc Crit Rev Oncol Hematol. 2002;43:63-76.

40. Gennari L, Merlotti D, Valleggi F, Martini G, Nuti R. Selective estrogen receptor modulators for postmenopausal osteoporosis: current state of development. Drugs Aging. 2007;24:361-379.

41. Delmas PD, Bjarnason NH, Mitlak BH, et al. Effects of raloxifene on bone mineral density, serum cholesterol concentrations, and uterine endometrium in postmenopausal women. $N$ Engl $J$ Med. 1997;337:1641-1647.

42. Lufkin EG, Whitaker MD, Nickelsen T, et al. Treatment of established postmenopausal osteoporosis with raloxifene: a randomized trial. J Bone Miner Res. 1998;13:1747-1754.

43. Ettinger B, Black DM, Mitlak BH, et al. Reduction of vertebral fracture risk in postmenopausal women with osteoporosis treated with raloxifene: results from a 3-year randomized clinical trial. Multiple Outcomes of Raloxifene Evaluation (MORE) Investigators. JAMA. 1999;282:637-645. Erratum: JAMA. 1999;282:2124.

44. Bryant HU, Glasebrook AL, Yang NN, Sato M. A pharmacological review of raloxifene. J Bone Miner Metab. 1996;14:1-9.

45. Weinstein RS, Parfitt AM, Marcus R, Greenwald M, Crans G, Muchmore DB. Effects of raloxifene, hormone replacement therapy, and placebo on bone turnover in postmenopausal women. Osteoporos Int. 2003;14:814-822. 
46. Prestwood KM, Gunness M, Muchmore DB, Lu Y, Wong M, Raisz LG. A comparison of the effects of raloxifene and estrogen on bone in postmenopausal women. J Clin Endocrinol Metab. 2000;85:2197-2202.

47. Rosati RL, Da Silva Jardine P, Cameron KO. Discovery and preclinical pharmacology of a novel, potent, nonsteroidal estrogen receptor agonist/antagonist, CP-336156, a diaryltetrahydronaphthalene. J Med Chem. 1998;41:2928-2931.

48. Yang X, Reinhold AR, Rosati RL, Liu KK. Enzyme-catalyzed asymmetric deacylation for the preparation of lasofoxifene (CP-336156), a selective estrogen receptor modulator. Org Lett. 2000;2:4025-4027.

49. Cameron K. Discovery of CP-336156, a potent estrogen agonist. San Francisco, CA: 219th ACS Nat Meeting; 2000. (MEDI 326).

50. Gennari L. Lasofoxifene (Pfizer). Curr Opin Investig Drugs. 2005;6:1067-1078.

51. Gennari L. Lasofoxifene: a new type of selective estrogen receptor modulator for the treatment of osteoporosis. Drugs Today (Barc). 2006; $42: 355-367$

52. Gennari L, Merlotti D, Martini G, Nuti R. Lasofoxifene: a third-generation selective estrogen receptor modulator for the prevention and treatment of osteoporosis. Expert Opin Investig Drugs. 2006;15:1091-1103.

53. Morello KC, Wurz GT, DeGregorio MW. Pharmacokinetics of selective estrogen receptor modulators. Clin Pharmacokinet. 2003;42:361-372.

54. Katzenellenbogen JA. D- 1, 2-Dyaril-3,4-dihydronaphthalenes: photofluorogenic ligands for the estrogen receptor. J Steroid Biochem. 1985;23:929-937.

55. Jhonson KA, Gardner MJ, Prakash C. In vivo and in vitro metabolites of a next-generation selective estrogen receptor modulator, lasofoxifene, in humans. Drug Metab Rev. 2004;36:246.

56. Gardner M, Nishizawa Y, Wei G, Dogolo L, Calcagni A. A single-dose pharmacokinetic study of lasofoxifene in Japanese and Caucasian postmenopausal women [abstract]. J Bone Miner Res. 2004;19:M469.

57. Gardner M, Taylor A, Wei G, Calcagni A Jr, Duncan B, Milton A. Clinical pharmacology of multiple doses of lasofoxifene in postmenopausal women. J Clin Pharmacol. 2006;46:52-58.

58. Roman D, Bramson C, Ouellet D, Randinitis E, Gardner M. Effect of lasofoxifene on the pharmacokinetics of digoxin in healthy postmenopausal women. J Clin Pharmacol. 2005;45:1407-1412.

59. Moller RA, Fisher JM, Taylor AE, et al. Effects of steady-state lasofoxifene on CYP2D6- and CYP2E1-mediated metabolism. Ann Pharmacother. 2006;40:32-37.

60. Bramson C, Ouellet D, Roman D, Randinitis E, Gardner MJ. A singledose pharmacokinetic study of lasofoxifene in healthy volunteers and subjects with mild and moderate hepatic impairment. J Clin Pharmacol. 2006;46:29-36.

61. Ke HZ, Paralkar VM, Grasser WA. Effects of CP-336,156, a new, nonsteroidal estrogen agonist/antagonist, on bone, serum cholesterol, uterus and body composition in rat models. Endocrinology. 1998;139:2068-2076.

62. Ke HZ, Qi H, Chidsey-Frink KL, et al. Effects of different dose regimens of lasofoxifene (CP-336,156) in preventing bone loss in ovariectomized rats. J Bone Miner Res. 2000;15:S1-S310.

63. Ke HZ, Foley GL, Simmons HA, Shen V, Thompson DD. Long-term treatment of lasofoxifene preserves bone mass and bone strength and does not adversely affect the uterus in ovariectomized rats. Endocrinology. 2004;145:1996-2005.

64. Ke HZ, Qi H, Crawford DT, et al. Lasofoxifene (CP-336-156), a selective estrogen receptor modulator, prevents bone loss induced by aging and orchidectomy in the adult rat. Endocrinology. 2000;141: 1338-1344.

65. Ke HZ, Oi H, Chidsey-Frink KL, et al. Lasofoxifene (CP-336,156) protects against the age-related changes in bone mass, bone strength, and total serum cholesterol in intact aged male rats. J Bone Miner Res. 2001;16:765-773

66. Kharode YP, Green PD, Marzolf JT, et al. Comparison of the effects of bazedoxifene, raloxifene, lasofoxifene and risedronate, co-treatment on h-PTH-induced reversal of established osteopenia in ovariectomized rats [abstract]. J Bone Miner Res. 2003;18:S273, SU387.
67. Cohen LA, Pittman B, Wang CX, et al. LAS, a novel selective estrogen receptor modulator with chemopreventive and therapeutic activity in the $\mathrm{N}$-nitroso-N-methylurea-induced rat mammary tumor model. Cancer Res. 2001;61:8683-8688.

68. Chesworth R, Zawistoski MP, Lefker BA, et al. Tetrahydroisoquinolines as subtype selective estrogen agonists/antagonists. Bioorg Med Chem Letters. 2004;14:2729-2733.

69. Cappon GD, Horimoto M, Hurtt ME. Reproductive toxicity assessment of lasofoxifene, a selective estrogen receptor modulator (SERM), in male rats. Birth Defects Res B Dev Reprod Toxicol. 2004;71: 142-149.

70. Terry KK, Cappon GD, Hurtt ME, Tassinari MS, Gupta U. Reproductive toxicity assessment of lasofoxifene, a selective estrogen receptor modulator (SERM), in female rats. Birth Defects Res B Dev Reprod Toxicol. 2004;71:150-160.

71. Weisenburger WP, Hagler AR, Tassinari MS. Pre- and postnatal development studies of lasofoxifene, a selective estrogen receptor modulator (SERM), in Sprague-Dawley rats. Birth Defects Res B Dev Reprod Toxicol. 2004;71:171-184.

72. Ozolins TRS, Gupta U. Embryo/fetal toxicity assessment of lasofoxifene, a selective estrogen receptor modulator (SERM), in rats and rabbits. Birth Defects Res B Dev Reprod Toxicol. 2004;71: 161-170.

73. Cohen IR, Wierda D, Griffey KI, Fisher LF, Francis Pc. The selective estrogen receptor modulator, raloxifene: a segment II/III delivery study in rats. Reprod Toxicol. 1998;12:271-288.

74. McClung MR, Siris E, Cummings S, et al. Prevention of bone loss in postmenopausal women treated with lasofoxifene compared with raloxifene. Menopause. 2006;13:377-386.

75. Anon. Background document for meeting of Advisory Committee for Reproductive Health Drugs. NDA 22-242. Lasofoxifene Tartrate (Proposed trade name: FABLYN). September 8, 2008. Accessed on Dec 10, 2008. Available from: http://www.fda.gov/ohrms/dockets/ ac/08/briefing/2008-4381b1-01-FDA.pdf.

76. Anon. Fablyn ${ }^{\circledR}$ (lasofoxifene tartrate) $0.5 \mathrm{mg}$ tablets NDA 22-242. Reproductive Health Drugs Advisory Committee briefing document. September 8, 2008. Accessed on Dec 10, 2008. Available at http://www. fda.gov/ohrms/dockets/ac/08/briefing/2008-4381b1-02-Pfizer.pdf.

77. Moller R, Fisher J, Taylor A, Kolluri S, Gardner M. Effect of food on the pharmacokinetics of lasofoxifene in healthy postmenopausal women [abstract]. J Bone Miner Res. 2004;19:SU487.

78. Lee A, Radecki D, Wolter K, et al. Lasofoxifene phase 2 and phase 3 clinical trial design and strategy [abstract]. J Bone Miner Res. 2005;20:M384.

79. Day W, Martel J, Lee A. Lasofoxifene phase 2 dose response analysis in postmenopausal women [abstract]. J Bone Miner Res. 2005;20:M385.

80. Moffett AH, Ettinger M, Bolognese M, et al. Lasofoxifene, a next generation SERM, is effective in preventing loss of BMD and reducing LDL-C in postmenopausal women [abstract]. J Bone Miner Res. 2004;19:SA426.

81. Portman DJ, Moffett AH, Bachman GA, West C, Symons J. Lasofoxifene, a selective estrogen receptor modulator, improves objective measures of vaginal atrophy. Obstet Gynecol. 2004;103: 25S-26S.

82. Ettinger M, Schwartz E, Emkey R, et al. Lasofoxifene: a next generation selective estrogen receptor modulator (SERM) in the prevention of bone loss in postmenopausal women. New Orleans, LA: Presented at the 86th Annual Meeting of the Endocrine Society; June 16-19, 2004.

83. Anon. Ligand earns milestone from Pfizer as lasofoxifene enters phase II for osteoporosis; first of three late-stage SERM products advancing prospects of future royalties. San Diego, CA: Ligand Pharmaceuticals International Inc; 2000.

84. McClung M, Omizo M, Weiss S, et al. Comparison of lasofoxifene and raloxifene for the prevention of bone loss in postmenopausal women [abstract]. J Bone Miner Res. 2004;19:SA424.

85. McClung M, Portman D, Emkey R, et al. Comparison of the extraskeletal effects of lasofoxifene and raloxifene [abstract]. J Bone Miner Res. 2004;19:SA423. 
86. McClung M, Siris E, Cummings S, et al. Lasofoxifene increased BMD of the spine and hip and decreased bone turnover markers in postmenopausal women with low or normal BMD [abstract]. J Bone Miner Res. 2005;20:F429.

87. Davidson M, Moffett A, Welty F, et al. Extraskeletal effects of lasofoxifene on postmenopausal women [abstract]. J Bone Miner Res. 2005;20: SA428.

88. Eastell R, Reid DM, Vukicevic S, et al. The effects of lasofoxifene on bone turnover markers: the PEARL trial [abstract]. J Bone Miner Res. 2008;23:1287.

89. Glover SJ, Rogers A, Gossiel F, Eastell R. A randomized double blinded controlled trial of individual response in biochemical markers of bone turnover to lasofoxifene therapy [abstract]. J Bone Miner Res. 2008; 23:M507.

90. Cummings SR, Eastell R, Ensrud K, et al. The effects of lasofoxifene on fractures and breast cancer: 3-year results from the PEARL trial [abstract]. J Bone Miner Res. 2008;23:1288.

91. Goldstein SR. Not all SERMs are created equal. Menopause. 2006; 13:325-327.

92. Wang XN, Simmons HA, Salatto CT, Cosgrove PG, Thompson DD. Lasofoxifene enhances vaginal mucus formation without causing hypertrophy and increases estrogen receptor beta and androgen receptor in rats. Menopause. 2006;13:609-620.

93. Fleurence RL, Iglesias CP, Torgerson DJ. Economic evaluations of interventions for the prevention and treatment of osteoporosis: a structured review of the literature. Osteoporos Int. 2006;17:29-40.
94. Fleurence RL, Iglesias CP, Johnson JM. The cost effectiveness of bisphosphonates for the prevention and treatment of osteoporosis: a structured review of the literature. Pharmacoeconomics. 2007;25: 913-933.

95. Tosteson NA, Burge RT, Marshall DA, Lindsay R. Therapies for treatment of osteoporosis in US women: cost-effectiveness and budget impact considerations. Am J Manag Care. 2008;14:605-615.

96. Tosteson NA, Melton LJ, Dawson-Hughes B, et al. Cost-effective osteoporosis treatment thresholds: The United States perspective. Osteopros Int. 2008;19:437-447.

97. Stevenson N, Jones ML, De Nigris E, Brewer N, Davis S, Oakley J. A systematic review and economic evaluation of alendronate, etidronate, risedronate, raloxifene and teriparatide for the prevention and treatment of postmenopausal osteoporosis. Health Technol Assess. 2005;9:1-160.

98. Cauley JA, Norton L, Lippman ME, et al. Continued breast cancer risk reduction in postmenopausal women treated with raloxifene: 4-year results from the MORE trial. Multiple outcomes of raloxifene evaluation. Breast Cancer Res Treat. 2001;65:125-134. Correction: Breast Cancer Res Treat. 2001; 67.

99. Martino S, Cauley JA, Barrett-Connor E, et al. Continuing outcomes relevant to Evista: breast cancer incidence in postmenopausal osteoporotic women in a randomized trial of raloxifene. J Natl Cancer Inst. 2004;96:1751-1761.

\section{Core Evidence}

\section{Publish your work in this journal}

Core Evidence is an international, peer-reviewed open-access journal evaluating the evidence underlying the potential place in therapy of drugs throughout their development lifecycle from preclinical to postlaunch. The focus of each review is to evaluate the case for a new drug or class in outcome terms in specific indications and patient

\section{Dovepress}

groups. The manuscript management system is completely online and includes a very quick and fair peer-review system, which is all easy to use. Visit http://www.dovepress.com/testimonials.php to read real quotes from published authors. 